\title{
Controlled Release Properties of Zein-Fatty Acid Blend Films for Multiple Bioactive Compounds
}

\author{
Iskender Arcan and Ahmet Yemenicioğlu* \\ Department of Food Engineering, Faculty of Engineering, Izmir Institute of Technology, 35430, Gülbahçe Köyü, Urla, Izmir, Turkey \\ Supporting Information
}

ABSTRACT: To develop edible films having controlled release properties for multiple bioactive compounds, hydrophobicity and morphology of zein films were modified by blending zein with oleic $\left(\mathrm{C}_{18: 1}\right) \Delta^{9}$, linoleic $\left(\mathrm{C}_{18: 2}\right) \Delta^{9,12}$, or lauric $\left(\mathrm{C}_{12}\right)$ acids in the presence of lecithin. The blend zein films showed 2-8.5- and 1.6-2.9-fold lower initial release rates for the model active compounds, lysozyme (LYS) and (+)-catechin (CAT), than the zein control films, respectively. The change of fatty acid chain length affected both CAT and LYS release rates while the change of fatty acid double bond number affected only the CAT release rate. The film morphologies suggested that the blend films owe their controlled release properties mainly to the microspheres formed within their matrix and encapsulation of active compounds. The blend films showed antilisterial activity and antioxidant activity up to $81 \mu \mathrm{mol}$ Trolox $/ \mathrm{cm}^{2}$. The controlled release of multiple bioactive compounds from a single film showed the possibility of combining application of active and bioactive packaging technologies and improving not only safety and quality but also health benefits of packed food.

KEYWORDS: active packaging, bioactive packaging, edible film, blend film, lysozyme, CAT

\section{INTRODUCTION}

In recent years, continuous efforts have been spent to improve safety and quality of food or to increase their shelf life by using novel packaging technologies. Active packaging containing antimicrobials (antimicrobial packaging) or antioxidants (antioxidant packaging) is among the most promising packaging technologies, since its application can inhibit pathogenic and spoilage microorganisms and lipid oxidation in food, respectively. The addition of bioactive compounds into packaging materials has also initiated bioactive packaging, a novel packaging concept that targets enriching packed food with bioactive compounds and improving their potential health benefits. $^{2}$

Because of the health concerns of the consumers and environmental problems, there is an increasing trend to use natural active compounds and edible films in active packaging. Therefore, antimicrobial enzymes including lysozyme (LYS), lactoperoxidase and glucose oxidase, bacteriocins, and natural antimicrobial and antioxidants such as plant phenolics and essential oils have been extensively tested in different edible packaging materials. ${ }^{3-5}$ The use of natural phenolic compounds in active packaging attracts a particular interest, since these compounds show antimicrobial and antioxidant activity in food systems and increase health benefits of food because of their potential bioactive effects. ${ }^{2,6}(+)$-Catechins (CATs), a group of flavonoids $\left(\mathrm{C}_{6} \mathrm{C}_{3} \mathrm{C}_{6}\right)$, are frequently employed in foods, since it is economically feasible to extract these compounds from abundant sources such as green tea ${ }^{7}$ and they show well documented bioactive effects such as antioxidant, anticancerogenic, antidiabetic, and antihypertensive activities. ${ }^{8}$ LYS obtained from hen egg white is also among the most potential candidates for antimicrobial packaging, since it has a GRAS status and it shows good stability and activity in different films and food systems under refrigerated storage temperature.,
This enzyme is effective mainly on Gram-positive bacteria and shows its antimicrobial activity by splitting the bonds between $\mathrm{N}$-acetylmuramic acid and $\mathrm{N}$-acetylglucosamine of the peptidoglycan layer in the bacterial cell wall. Thus, the application of LYS in active packaging targets mainly inhibition of critical Gram-positive pathogenic bacteria such as Listeria monocytogenes that might cause deadly infections. ${ }^{10-12}$ LYS has recently been tested extensively in different plastic materials such as cellulose acetate, nylon, and $\mathrm{PVOH}^{4,13}$ and biopolymeric materials from zein, soy protein, carrageenan, whey protein, chitosan, alginate, and pullulan ${ }^{4,14}$ to develop antimicrobial packaging materials.

Antioxidant and antimicrobial packaging targets mainly the food surface on which oxidative and microbiological changes occur most intensively. ${ }^{15}$ A sufficient preservation effect could not be achieved unless the release rate of active compounds from the packaging materials to the food surface is adjusted considering the physical and chemical properties of food, lipid oxidation rate, growth kinetics of target pathogenic or spoilage microorganisms, and expected food shelf life. ${ }^{15,16}$ Different studies have been conducted to control the release rate of LYS in different plastic films from cellulose acetate, poly(vinyl alcohol), and glycerol/poly butylenes trephthalate and in different edible films from caseinate, zein, and chitosan. ${ }^{13,17-20}$ On the other hand, although the controlled release of CAT had been studied from polypropylene films, ${ }^{21,22}$ no studies are determined related to controlled release of CAT from edible films.

Received: February 11, 2014

Revised: July 10, 2014

Accepted: July 15, 2014

Published: July 15, 2014 
The incorporation of LYS into zein films or zein particles has recently gained an increasing interest, since (1) zein is the major coproduct of the oil and rapidly growing bioethanol industries, (2) it is one of the rare film forming proteins soluble in various organic solvents including ethanol, and (3) it provides an effective delivery system for LYS. ${ }^{9,23-29}$ The effectiveness of zein-based LYS delivery systems is due to the highly hydrophobic nature of the zein film matrix that contains very limited charges to cause binding and immobilization of LYS that is positively charged in food systems due to its high pI at $11.35 .^{30}$ The LYS activity is also highly stable during zein film making and during cold storage of precast zein films. ${ }^{9}$ Moreover, LYS release profiles of zein films could be changed effectively by modifying film morphology and hydrophobicity using composite and blend film making technologies. Gucbilmez et al. ${ }^{23}$ sustained LYS release from zein films by forming composites of these films with chickpea proteins. Arcan and Yemenicioğlu ${ }^{24}$ controlled LYS release from zein films by preparing composites of zein with different waxes. These authors reported that the LYS release profiles of zeinwax composites could be effectively modified by using different types of waxes that create different film morphologies and increase film tortuosity depending on their melting points. Ünalan et al. ${ }^{15}$ employed LYS with a mixture of CAT and gallic acid and showed the benefits of using controlled release technology in zein-wax composites applied for antimicrobial and antioxidant packaging of cheese. Not only composite films, but also blend films of zein prepared by forming emulsions of zein with the fatty acid oleic acid (OLE) in the presence of lecithin (LEC) have also been applied for controlled release of LYS. ${ }^{24}$ The preparation of zein blend films with OLE causes the formation of microspheres within the film matrix, and this increases barriers against diffusion of encapsulated LYS. ${ }^{24}$ The aim of the current work is to investigate the effects of using different fatty acids, OLE $\left(\mathrm{C}_{18: 1}\right) \Delta,{ }^{9}$ linoleic (LIN) $\left(\mathrm{C}_{18: 2}\right) \Delta,{ }^{9,12}$ and lauric (LAU) $\left(\mathrm{C}_{12}\right)$, in zein blend film making to obtain different release profiles for LYS and CAT at the same film system. It was proposed that the use of fatty acids with different chain length, conformation, and saturation level could create different types of zein microspheres and morphologies and this could be exploited to obtain films with different release profiles for LYS and CAT. The use of LAU in blend film making could contribute not only to the controlled release properties of active compounds, but it could also provide an additional antimicrobial effect to films, since it is an active fatty acid with potent antimicrobial activity. ${ }^{31}$ This is one of the first studies that aimed in developing a scientific basis for edible packaging materials having controlled release properties for multiple active compounds capable of showing antimicrobial and antioxidant effects not only in packed food (active packaging) but also in the human physiological system after consumption of the enriched packed food (bioactive packaging).

\section{MATERIALS AND METHODS}

Materials. Maize zein (batch number: 058 K0093), (+)-CAT hydrate ( $\geq 98 \%$ ), Micrococcus lysodeikticus, OLE (tech. 90\%), LIN (minimum 99\%), and LAU ( $\geq 98 \%$ ) were from Sigma-Aldrich Chem. Co. (St. Louis, MO, USA). Soybean L- $\alpha$-LEC and glycerol were from Merck (Darmsdadt, Germany). All other chemicals were reagent grade. Fresh hen eggs used in production of LYS were obtained from a supermarket in Izmir (Turkey).

LYSs Used in the Study. The partially pure (PP) LYS was produced by the selective precipitation of egg white proteins other than this enzyme according to the method described by Mecitoglu et al. ${ }^{9}$ The enzyme was lyophilized by using a freeze drier (Labconco, FreeZone, 6 L, Kansas City, MO, USA) and stored at $-18^{\circ} \mathrm{C}$ until it was used in film-making. The pure commercial (PC) LYS (protein and specific activity values specified in the manual are $\geq 90 \%$ and $\geq 40000$ units/mg protein, respectively) was obtained from Sigma-Aldrich Chem. Co. (St. Louis, MO, USA). The specific activities of PP LYS and PC LYS determined by the method described in this study were 40477 and $78984 \mathrm{U} / \mathrm{mg}$ protein, respectively. The protein content of the LYS preparations was tested by the classical Bradford method by using bovine serum albumin as the standard. The impurities in the PP LYS and the purity of PC LYS were tested by sodium dodecyl sulfate polyacrylamide gel electrophoresis (SDS-PAGE) according to the method of Laemmli ${ }^{32}$ using a $12 \%$ separating gel and a $4 \%$ stacking gel. Proteins bands were stained with silver salts described by Blum et al. $^{33}$

Preparations of Zein Films. The films were produced by modifying the methods described in Padgett et al. ${ }^{34}$ and Arcan and Yemenicioglu. ${ }^{33}$ Briefly, $1.4 \mathrm{~g}$ of zein was dissolved with $8.1 \mathrm{~mL}$ of ethanol (96\%) by mixing slowly with a magnetic stirrer for $25 \mathrm{~min}$, and $0.4 \mathrm{~mL}$ of glycerol was then added to the medium as plasticizer. The mixture was then heated under continuous mixing until it started to boil. The boiling was conducted for $5 \mathrm{~min}$, and the film-making solution was cooled to room temperature. CAT $(100 \mathrm{mg} / \mathrm{g}$ filmforming solution) and PC LYS (Sigma-Aldrich Chem. Co.) or PP LYS obtained according to Mecitoglu et al. ${ }^{9}$ were then added into filmforming solutions. PC LYS (78984 U/mg protein) and PP LYS ( $40477 \mathrm{U} / \mathrm{mg}$ protein) were used at the concentrations of 11.7 and $23.4 \mathrm{mg}$ lyophilized powder/g of film-forming solution, respectively (the final PC LYS, PP LYS, and CAT concentrations in cast and dried films were $0.7,1.4$, and $6 \mathrm{mg} / \mathrm{cm}^{2}$, respectively). The PP LYS concentration used in film making is 2 -fold higher than that used in zein films successfully applied to control microbial development in actively packed ground beef patties. ${ }^{10}$ After addition of CAT and LYS, the mixtures were homogenized (Heidolph, Germany, rotor $\Phi=6.6$ $\mathrm{mm}$ tip) at $10000 \mathrm{rpm}$ for $4 \mathrm{~min}$. Then, $4.3 \mathrm{~g}$ portions of the homogenized film-forming solutions were cast into the glass templates $\left(\mathrm{W} \times \mathrm{L} \times \mathrm{H}: 8.5 \times 8.5 \times 0.4 \mathrm{~cm}^{3}\right)$ and dried for $19 \pm 2 \mathrm{~h}$ at $25^{\circ} \mathrm{C}$ in an incubator unless otherwise was stated. This homogenization and casting procedure was also used to obtain zein-fatty acid blend films by adding fatty acids (LAU, OLE, and LIN) and emulsifier LEC into film-forming solutions at $5-20 \%(\mathrm{w} / \mathrm{w})$ and $10 \%(\mathrm{w} / \mathrm{w})$ of zein, respectively. The fatty acids and LEC were added after the boiling step following cooling of zein film-forming solution to room temperature.

LYS Release Profiles of Films. For the release tests, film samples $\left(4.5 \times 4.5 \mathrm{~cm}^{2}\right)$ were placed between two glass frames (dimensions: inside, $4 \times 4 \mathrm{~cm}^{2}$; outside, $6 \times 6 \mathrm{~cm}^{2}$ ). The edges of the glass frames were carefully sealed with paraffin film, and the glass apparatus containing the film was placed horizontally at the bottom of a $500 \mathrm{~mL}$ glass beaker containing $150 \mathrm{~mL}$ of distilled water at $4{ }^{\circ} \mathrm{C}$. Four $0.5 \mathrm{~cm}$ diameter glass rods were placed below the frame at the corners to increase water circulation, and the overall apparatus (the $500 \mathrm{~mL}$ beaker) was placed onto an orbital shaker working at $80 \mathrm{rpm}$ in an incubator at $4{ }^{\circ} \mathrm{C}$. The LYS activity released from the films was monitored by taking $0.25 \mathrm{~mL}(\times 3)$ aliquots from the release test solution at different time intervals. The release tests were conducted until equilibrium was reached for release of LYS or an insignificant increase was observed in the activity of released LYS. The LYS activities of collected aliquots were determined spectrophotometrically at $660 \mathrm{~nm}$ by using a Shimadzu spectrophotometer (Model 2450, Tokyo, Japan) equipped with a constant temperature cell holder working at $30{ }^{\circ} \mathrm{C}$. The Micrococcus lysodeikticus solution prepared in $0.05 \mathrm{M}, \mathrm{pH} 7.0 \mathrm{Na}$ phosphate buffer $(0.26 \mathrm{mg} / \mathrm{mL})$ was used as substrate during activity determination. The reaction mixture was formed by mixing 0.1 or $0.25 \mathrm{~mL}$ of release test medium (depending on LYS activity) and 2.4 or $2.25 \mathrm{~mL}$ of substrate solution to reach a final reaction volume of $2.5 \mathrm{~mL}$. The enzyme activities were calculated from the slopes of initial linear portions of absorbance versus time curves and were expressed as unit $(\mathrm{U})$ that was defined as the number of 0.001 changes in absorbance in $1 \mathrm{~min}$. All calculations were corrected by considering the activity removed by collected aliquots 

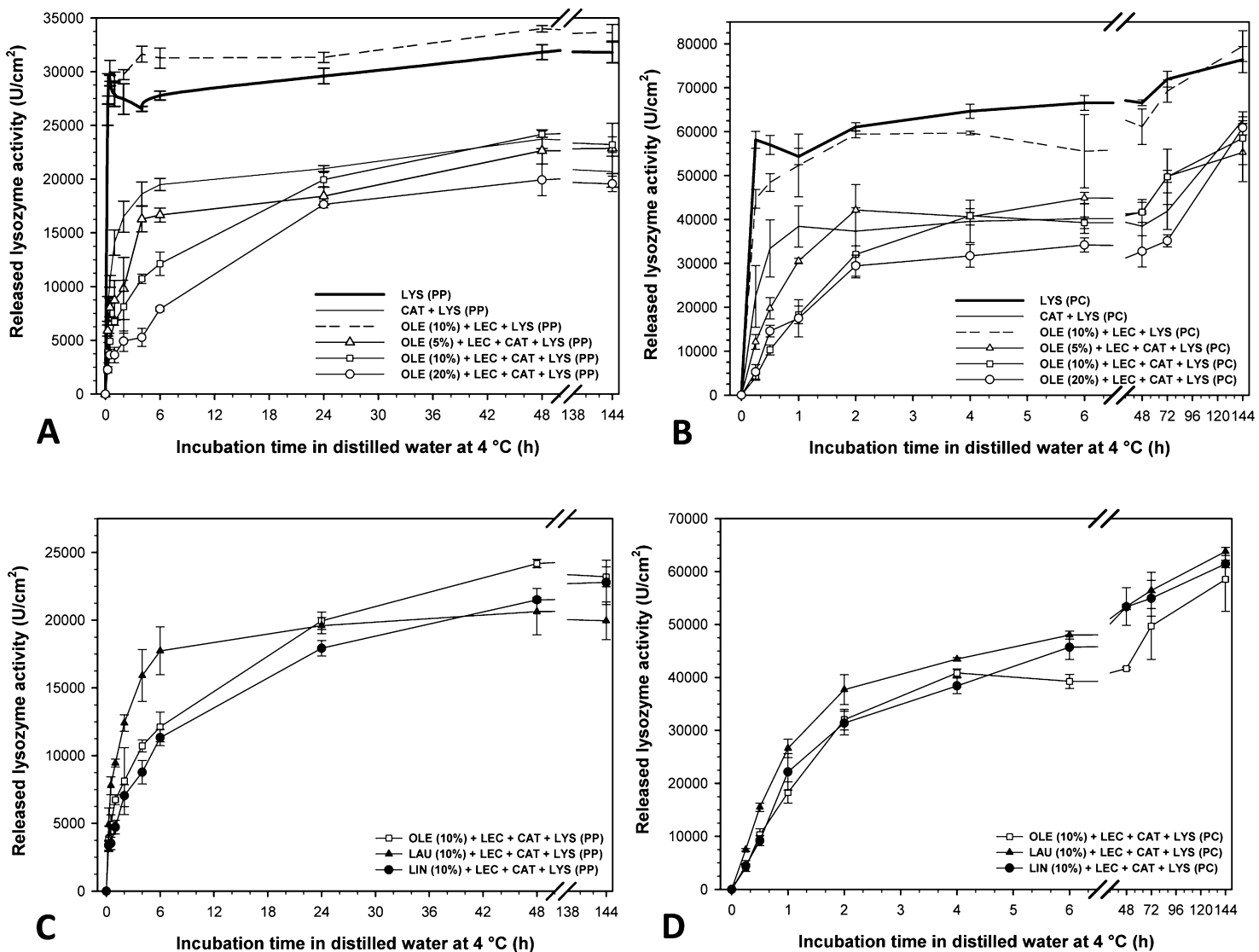

Figure 1. Effect of CAT and blend film making on release profiles of (A, C) PP LYS and (B, D) PC LYS. CAT: catechin; LYS: lysozyme; OLE: oleic acid; LAU: lauric acid; LIN: linoleic acid; LEC: lecithin.

during sampling. The total LYS activity released from each film corresponded to maximum units released per centimeter squared of the films $\left(\mathrm{U} / \mathrm{cm}^{2}\right)$ at the equilibrium. All activity measurements were conducted three times. The release curves were formed by plotting calculated released activities $\left(\mathrm{U} / \mathrm{cm}^{2}\right)$ versus incubation time $(\mathrm{h})$. The initial release rates of LYS were determined from the slope of the initial linear portion of the release curve. The release rates were expressed as units per centimeters squared per hour $\left(\mathrm{U} /\left(\mathrm{cm}^{2} \mathrm{~h}\right)\right)$.

CAT Release Profiles and Antioxidant Capacity of Films. To determine the CAT release profiles of films, the release tests were conducted in water as described in the LYS Release Profiles of Films section. The soluble CAT content of the collected samples was determined spectrophotometerically at $510 \mathrm{~nm}$ according to the colorimetric method of Meyers et al. ${ }^{35}$ used for quantification of flavonoids. The total soluble CAT contents released from the films were expressed as milligrams of CAT per centimeter squared of the films $\left(\mathrm{mg} / \mathrm{cm}^{2}\right)$ using the calibration curve prepared by CAT. All concentration measurements were conducted three times. The release curves were formed by plotting the calculated released phenolic contents $\left(\mathrm{mg} / \mathrm{cm}^{2}\right)$ versus time $(\mathrm{h})$. The initial CAT release rates were determined from the slope of the initial linear portion of release curve. The release rates were expressed as milligrams per centimeter squared per hour $\left(\mathrm{mg} /\left(\mathrm{cm}^{2} \mathrm{~h}\right)\right)$. The antioxidant capacity of the films was based on calculating the Trolox equivalent antioxidant capacity (TEAC) of their total released CAT content at the equilibrium. The percentage of free soluble CAT in the films was determined by the formula of (total released CAT/initial CAT added) $\times 100$. The TEAC of CAT was determined by using the spectrophotometric ABTS radical cation decolourization assay conducted at $734 \mathrm{~nm} .{ }^{36}$ The results were expressed as micromoles of Trolox equivalents released per centimeter squared of films $\left(\mu \mathrm{mol}\right.$ Trolox $\left./ \mathrm{cm}^{2}\right)$.

Antimicrobial Potential of Films. The antimicrobial potentials of films were tested by using Listeria innocua (NRRL B-33314; supplied from USDA, Microbial Genomics and Bioprocessing Research Unit, Peoria, IL, USA) as a test microorganism. During antimicrobial tests, 18 discs ( $1.3 \mathrm{~cm}$ in diameter) were prepared from each film by a cork borer. Total of 15 discs were selected randomly, and 3 discs were placed into each Petri dish containing nutrient agar previously inoculated with $0.1 \mathrm{~mL}$ of bacterial culture. The inocula were prepared in peptone water $(0.1 \%)$ by using $48 \mathrm{~h}$ culture grown in nutrient agar. The cell concentration was set to $1.0 \mathrm{McFarland}$ unit that corresponded to $13 \times 10^{7} \mathrm{CFU} / \mathrm{mL}$. The Petri dishes containing discs of films were incubated first at $4{ }^{\circ} \mathrm{C}$ for $4 \mathrm{~h}$ to prevent rapid diffusion of the LYS, and then, second they were incubated at $37{ }^{\circ} \mathrm{C}$ for $36 \mathrm{~h}$ for microbial growth. The diameter of the zones formed around the discs was measured by using a calliper, and the results were expressed as average zone areas $\left(\mathrm{mm}^{2}\right)$.

Scanning Electron Microscopy (SEM) of Films. The cross sections and surfaces of selected films were monitored by using SEM (Philips XL 30S FEG, FEI Company, Netherlands) under high vacuum mode at an operating voltage at $3 \mathrm{kV}$. The film cross sections were obtained by crushing films following freezing in liquid nitrogen. The samples were then gold coated with a sputter coater (Emitech K550X, Quorum Technologies Inc., UK) under $15 \mathrm{~mA}$ for $60 \mathrm{~s}$. The thickness of the films was measured from SEM cross-sectional views of films by using Scandium software (Olympus Soft Imaging Solutions GmbH, Münster, Germany).

Mechanical Properties of Films. Tensile strength at break, elongation at break, and elastic modulus were determined using a Texture Analyzer TA-XT2 (Stable Microsystems, Godalming, UK) according to ASTM standard method D 882-02. ${ }^{37}$ The films used in mechanical tests were conditioned by extending the standard drying period from 19 to $48 \mathrm{~h}$ at $25{ }^{\circ} \mathrm{C}$ and conducting drying at $50 \% \mathrm{RH}$ using a controlled test cabinet (TK 120, Nüve, Turkey). Films were cut into $5 \mathrm{~mm}$ wide and $80 \mathrm{~mm}$ length strips, initial grip distance was 
Table 1. Some Kinetic Parameters Determined from Release Curves of LYS and Antilisterial Potential of Films

\begin{tabular}{|c|c|c|c|c|c|}
\hline \multicolumn{3}{|c|}{ film composition } & \multirow[b]{2}{*}{$\begin{array}{l}\text { initial LYS release rate } \\
\left(\mathrm{U} /\left(\mathrm{cm}^{2} \mathrm{~h}\right)\right)\end{array}$} & \multirow[b]{2}{*}{$\begin{array}{l}\text { total released LYS activity } \\
\qquad\left(\mathrm{U} / \mathrm{cm}^{2}\right)\end{array}$} & \multirow[b]{2}{*}{$\begin{array}{l}\text { antimicrobial activity } \\
\left(\text { zone area as } \mathrm{mm}^{2}\right)\end{array}$} \\
\hline $\begin{array}{c}\mathrm{CAT} \\
\left(\mathrm{mg} / \mathrm{cm}^{2}\right)\end{array}$ & $\begin{array}{l}\text { fatty acid }{ }^{a} \\
\quad(\%)\end{array}$ & $\begin{array}{l}\operatorname{LEC}^{a} \\
(\%)\end{array}$ & & & \\
\hline- & - & - & - & - & no zone formation \\
\hline \multicolumn{6}{|c|}{ PP LYS $\left(1.4 \mathrm{mg} / \mathrm{cm}^{2}\right)$} \\
\hline- & - & - & $67472^{b c}$ & $32501 \pm 723 a^{d}$ & $65 \pm 10 \mathrm{a}, \mathrm{AB}$ \\
\hline- & 10(OLE) & 10 & 71152 & $34002 \pm 294 a$ & - \\
\hline 6.0 & - & - & 23124 & $23725 \pm 867 b c$ & $55 \pm 26 \mathrm{ab}, \mathrm{ABC}$ \\
\hline 6.0 & $5(\mathrm{OLE})$ & 10 & 17623 & $22861 \pm 2337 b c$ & - \\
\hline 6.0 & $10(\mathrm{OLE})$ & 10 & 10944 & $25011 \pm 1718 b$ & $35 \pm 4 b, C$ \\
\hline 6.0 & 20(OLE) & 10 & 7632 & $20972 \pm 886 c$ & - \\
\hline 6.0 & 10(LAU) & 10 & 16387 & $20941 \pm 1301 c$ & $537 \pm 52^{e}$ \\
\hline 6.0 & 10(LIN) & 10 & 8346 & $22789 \pm 1632 b c$ & $34 \pm 7 b, C$ \\
\hline \multicolumn{6}{|c|}{ PC LYS $\left(0.7 \mathrm{mg} / \mathrm{cm}^{2}\right)$} \\
\hline- & - & - & 137648 & $76408 \pm 2987 a$ & $73 \pm 26 a, A$ \\
\hline- & 10(OLE) & 10 & 113245 & $79468 \pm 3524 a$ & - \\
\hline 6.0 & - & - & 71418 & $62576 \pm 810 b$ & $38 \pm 7 b, C$ \\
\hline 6.0 & $5(\mathrm{OLE})$ & 10 & 41314 & $55255 \pm 6622 b$ & - \\
\hline 6.0 & 10(OLE) & 10 & 19762 & $58513 \pm 6041 b$ & $43 \pm 10 b, B C$ \\
\hline 6.0 & 20(OLE) & 10 & 19863 & $60868 \pm 1608 b$ & - \\
\hline 6.0 & $10(\mathrm{LAU})$ & 10 & 30798 & $63786 \pm 749 b$ & $506 \pm 7^{e}$ \\
\hline 6.0 & $10(\mathrm{LIN})$ & 10 & 18249 & $61427 \pm 696 b$ & $46 \pm 7 \mathrm{ab}, \mathrm{ABC}$ \\
\hline
\end{tabular}

${ }^{a}$ Concentrations of fatty acids and LEC as \% of zein (w/w). ${ }^{b}$ Determined from the slope of the initial linear portion of release curves. ${ }^{c}$ Time periods of data used in best fitting curves were between 0 and 0.5 h. $r^{2}$ values of curves were between $0.6825-0.9994 .{ }^{d}$ Different letters $(\mathrm{a}-\mathrm{c}$; A-C) in each column show the significant difference at $P<0.05$. Small letters indicate the differences within each enzyme type. Capital letters indicate the differences within all given results at the column. ${ }^{e}$ Not included in statistical analysis.

$50 \mathrm{~mm}$, and crosshead speed was $50 \mathrm{~mm} / \mathrm{min}$. At least seven replicates of each film were tested.

Statistical Analysis. For the determination of effects of film compositions on antimicrobial potentials and mechanical properties of films analysis of variance (ANOVA) was applied using Minitab 15 (Minitab Inc., State College, PA, USA). Multiple comparisons of means were performed using Fisher's least significant difference (LSD) method with a significance threshold of $P<0.05$.

\section{RESULTS AND DISCUSSION}

Effect of CAT and Blend Film Making with OLE on LYS Release Profiles. In the zein film system, the phenolic compounds including CAT not only serve as an active component but they also affect film morphology, since they interact with the film matrix via hydrogen bonding to available zein carbonyl groups. ${ }^{24}$ The morphological changes in zein films caused by CAT are particularly important, since they affect the film porosity, thus the controlled release properties of films. ${ }^{24,38}$ Arcan and Yemenicioğlu ${ }^{24}$ clearly showed the concentration-dependent contribution of CAT in sustained release of LYS form zein and zein-carnauba wax composite films. In the current work, the contribution of CAT in LYS release properties of zein films and zein-OLE (10\%) blend films are seen in Figure 1A, B. The control zein films and control zein-OLE (10\%) blend films lacking CAT showed 2.9and 8.5-fold higher release rates for PP LYS, and 1.9- and 7.5fold higher release rates for PC LYS than CAT-containing zein films and zein-OLE (10\%) blend films, respectively (Table 1). The SEM photos for cross sections (Figure 2A-D) and surfaces (Supporting Information, Figure S1) of zein films and zein-OLE (10\%) blend films containing and lacking CAT clearly showed the reduced film porosity by incorporation of CAT into films. Thus, it is clear that the CAT used as active compound also contributed to the sustained LYS release rates of zein films. On the other hand, the 2.1- and 3.6-fold lower release rates of CAT-containing zein-OLE (10\%) blend films for PP and PC LYS than CAT-containing zein films could be related with the differences in morphological properties of these films. The morphological changes of zein film structure when it is mixed with OLE without use of an emulsifier was recently explained by Wang et al. ${ }^{39}$ According to these authors, the morphological changes in the zein-OLE film system occurred at three steps: (1) formation of large numbers of OLE-coated zein microspheres, (2) partial melting of the microspheres by means of OLE, and (3) transformation of a sponge-like morphology by interconnection of microspheres with channels and tunnels. Arcan and Yemenicioğlu ${ }^{24}$ who employed the zein-OLE blend films for controlled release of LYS also reported the presence of microspheres within the zein-OLE films and attributed the sustained release properties of these blend films to encapsulation of LYS within the microspheres. However, different from Wang et al., ${ }^{39}$ these workers conducted the blending process by using LEC emulsifier, and they did not observe the presence of interconnections among the formed self-standing microspheres. In this work, the presence of self-standing microspheres was also observed in the SEM photos of both CAT-containing and -lacking zeinOLE blend films that were prepared by using emulsifier LEC (Figure 2C, D). These results suggest that the repulsion formed by negative charges of LEC that interacted with the OLEcoating formed around zein microspheres. This might prevent the interaction and melting down of the microspheres and enables the formation of self-standing microspheres different from the spongelike structure observed by Wang et al. ${ }^{39}$ It is also worth to note that the CAT reduced the sizes of microspheres and caused an increase in the number of microspheres. On the other hand, it is important to report that the total released PC or PP LYS activity from CATcontaining zein and zein-OLE (10\%) films at the equilibrium 


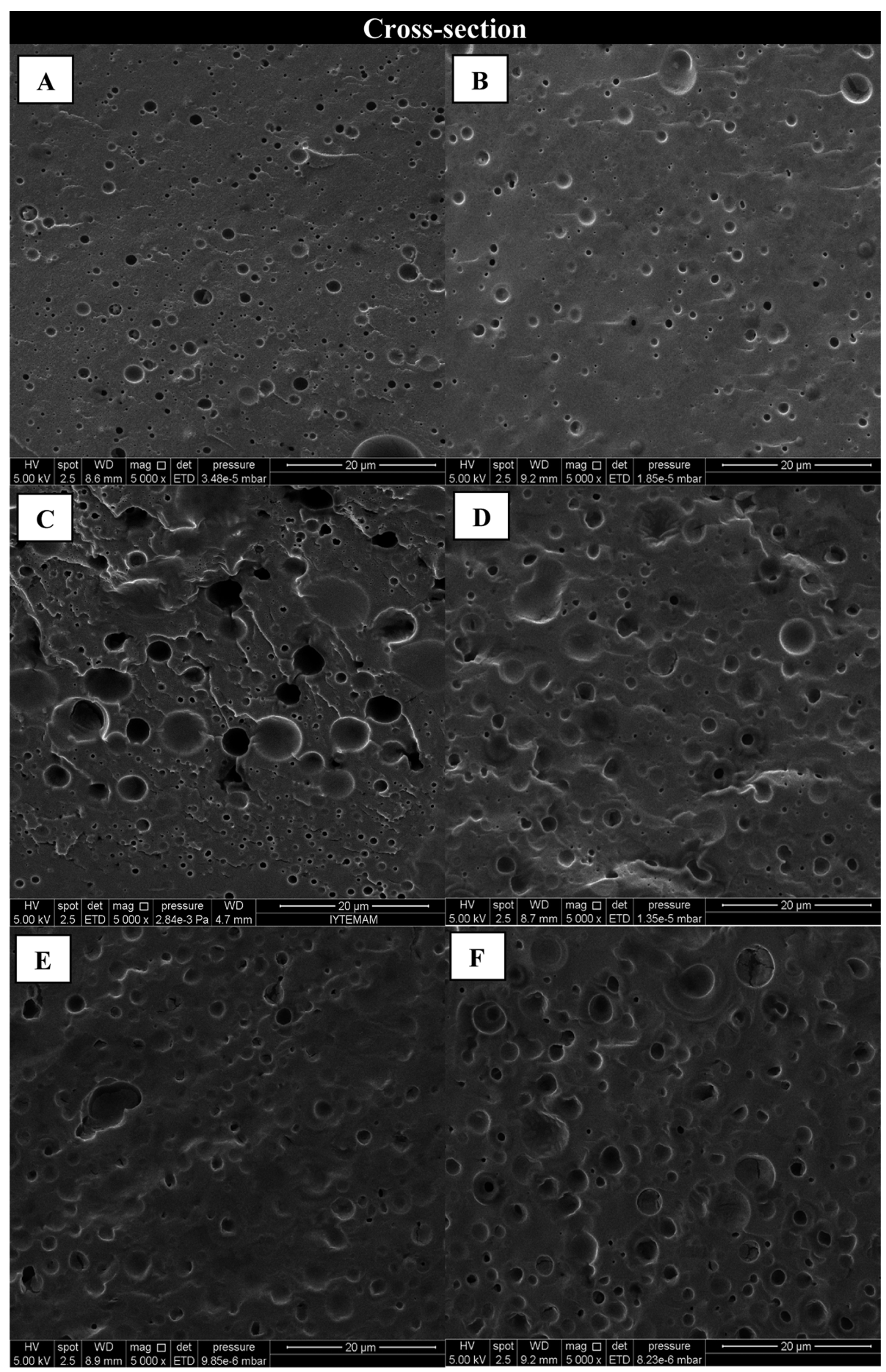

Figure 2. Cross-sectional SEM images of developed films: (A) zein film containing PP LYS $\left(1.4 \mathrm{mg} / \mathrm{cm}^{2}\right)$; (B) zein film containing CAT (6 mg/ $\mathrm{cm}^{2}$ ) and PP LYS $\left(1.4 \mathrm{mg} / \mathrm{cm}^{2}\right)$; (C) blend film containing OLE (10\%) and PP LYS $\left(1.4 \mathrm{mg} / \mathrm{cm}^{2}\right)$; (D) blend film containing OLE (10\%), CAT (6 $\left.\mathrm{mg} / \mathrm{cm}^{2}\right)$, and PP LYS $\left(1.4 \mathrm{mg} / \mathrm{cm}^{2}\right)$; (E) blend film containing LAU $(10 \%)$, CAT $\left(6 \mathrm{mg} / \mathrm{cm}^{2}\right)$, and PP LYS $\left(1.4 \mathrm{mg} / \mathrm{cm}^{2}\right)$; $(\mathrm{F}) \mathrm{blend}$ film containing LIN (10\%), CAT $\left(6 \mathrm{mg} / \mathrm{cm}^{2}\right)$, and PP LYS $\left(1.4 \mathrm{mg} / \mathrm{cm}^{2}\right)$. CAT: catechin; LYS: lysozyme; OLE: oleic acid; LAU: lauric acid; LIN: linoleic acid; LEC: lecithin.

is $18-27 \%$ lower than those of their CAT-lacking controls. This result suggests the trapping or immobilization of part of LYS within zein and zein-OLE (10\%) films when CAT was incorporated into films. On the other hand, there are no significant differences in total released PC or PP LYS activities from control zein films and zein-OLE (10\%) films lacking CAT $(P>0.05)$. Thus, it also appeared that the blend film making with OLE and the formation of microspheres within films did not cause considerable LYS trapping and immobilization.

Effect of OLE Concentration on LYS Release Profiles of Blend Films. In order to determine the effect of fatty acid concentration in release profiles of blend films, the OLE concentration of $10 \%$ was changed as $5 \%$ and $20 \%$ (Figure $1 \mathrm{~A}$, B). The results clearly showed that the increase of OLE fraction within blend films caused a reduction in release rates for both 
Table 2. Some Kinetic Parameters Determined from Release Curves of CAT and Antioxidant Activity of Films

\begin{tabular}{|c|c|c|c|c|c|}
\hline \multicolumn{3}{|c|}{ film composition } & \multirow[b]{2}{*}{ initial CAT release rate $\left(\mathrm{mg} /\left(\mathrm{cm}^{2} \mathrm{~h}\right)\right)$} & \multirow[b]{2}{*}{ total released CAT $\left(\mathrm{mg} / \mathrm{cm}^{2}\right)$} & \multirow[b]{2}{*}{ antioxidant activity $\left(\mu \mathrm{mol}\right.$ Trolox $\left./ \mathrm{cm}^{2}\right)$} \\
\hline CAT $\left(\mathrm{mg} / \mathrm{cm}^{2}\right)$ & fatty $\operatorname{acid}^{a}(\%)$ & $\operatorname{LEC}^{a}(\%)$ & & & \\
\hline \multicolumn{6}{|c|}{ PP LYS (1.4 mg/cm²) } \\
\hline 6.0 & - & - & $1.76^{b}$ & $4.8 \pm 0.2 a^{c}$ & $77.1 \pm 3.0 \mathrm{a}$ \\
\hline 6.0 & 10(OLE) & 10 & 0.61 & $4.3 \pm 0.1 b$ & $69.3 \pm 1.7 b$ \\
\hline 6.0 & 10(LAU) & 10 & 1.10 & $4.7 \pm 0.1 \mathrm{a}$ & $76.4 \pm 1.5 a$ \\
\hline 6.0 & 10(LIN) & 10 & 0.77 & $5.0 \pm 0.1 \mathrm{a}$ & $80.7 \pm 1.6 a$ \\
\hline
\end{tabular}

${ }^{a}$ Concentrations of fatty acids and LEC as \% of zein $(\mathrm{w} / \mathrm{w}) .{ }^{b}$ Time periods $(\mathrm{h})$ of data used in best fitting curves were between 0 and $1 \mathrm{~h} . r^{2}$ values of curves were between 0.6110 and 0.7491 . ${ }^{c}$ Different letters in each column show significant difference $P<0.05$.

PC and PP LYS. The initial release rate of PP LYS reduced 1.4to 1.6 -fold as a concentration-dependent manner when OLE concentration in blend films increased between 5\% and 20\%. On the other hand, the increase of OLE concentration within blend films from $5 \%$ to $10 \%$ caused almost 2 -fold reduction in initial release rate of PC LYS, but further increase of OLE concentration did not affect the initial release rate of PC LYS (Table 1). These results clearly showed the possibility of controlling LYS release rate of CAT-containing zein-OLE blend films by changing fatty acid concentration within the films.

Effect of Different Fatty Acids on LYS Release Profiles of Blend Films. To determine the effects of different fatty acids on LYS release profiles of CAT-containing blend films, LIN and LAU at $10 \%(\mathrm{w} / \mathrm{w})$ of zein were also used in film making. The selected fatty acids enabled determining the possible effects of carbon chain length $\left(\mathrm{C}_{12}\right.$ or $\left.\mathrm{C}_{18}\right)$, number of double bonds $\left(\mathrm{C}_{18: 1}\right.$ or $\left.\mathrm{C}_{18: 2}\right)$, and fatty acid tail conformation (LIN has more bent tail than OLE) in LYS release properties (Supporting Information, Figure S2). The LYS release curves of films clearly showed the more different release profiles of LAUcontaining blend films than LIN- and OLE-containing blend films (Figure 1C, D). In fact, the initial PP LYS and PC LYS release rates of LAU-containing blend films were 1.6- to 2.0fold higher than those of OLE- and LIN-containing blend films (Table 1). These results clearly showed the reduced diffusion barriers for LYS when fatty acid chain length was reduced from $\mathrm{C}_{18}$ to $\mathrm{C}_{12}$. On the other hand, the similar release profiles of LIN- and OLE-containing blend films also showed that the presence of one or two double bonds and the resulting conformational differences at the fatty acid aliphatic tails has no contribution in LYS release properties of blend films. The SEM photos of blend films obtained with LIN and LAU also showed the presence of self-standing microspheres in these films (Figure 2E, F). Thus, it is once more conformed that different fatty acids emulsified with LEC in the zein film system caused self-standing microspheres within the blend films. Moreover, it was also observed that microspheres in OLE- and LINcontaining blend films were larger and more intensive than those observed for LAU-containing films. Thus, it appeared that the higher LYS release rate of zein-LAU blend films than zein-OLE and zein-LIN films is related with the reduced fraction of LYS encapsulated within the microspheres. This result supported our hypothesis that the microspheres formed in zein-fatty acid blend films play a very important role in controlling LYS release rates.

Effect of Enzyme Purity on LYS Release Profiles of Zein and Blend Films. In this work, the use of LYS preparations at different purities aimed to test the magnitude of potential variations in the effectiveness of formed controlled release mechanisms. The comparison of the overall results for release tests clearly showed the higher release rates obtained for PC LYS than PP LYS. Almost 2-fold (78984 U/mg PC protein $/ 40477 \mathrm{U} / \mathrm{mg} \mathrm{PP}$ protein $=1.95$ ) higher purity of PC LYS than PP LYS resulted with 1.6-3-fold higher release rates of PC LYS than the PP LYS from similar films. The results of SDS-PAGE clearly showed the quite similar moleculare weights (MWs) of PP and PC LYS centered around $12 \mathrm{kDa}$ (Supporting Information, Figure S3). The SDS-PAGE profiles of PC LYS did not indicate any considerable protein impurities within this preparation except a thin band appeared at $11 \mathrm{kDa}$. On the other hand, as expected, the electrophoresis results showed the presence of different protein impurities in the PP LYS. The protein bands observed as impurities in PP LYS between 43 and $65 \mathrm{kDa}$ concentrate around $46-47 \mathrm{kDa}$ that might correspond to the ovalbumin fraction reported to have a MW of $45 \mathrm{kDa}^{40}$ Dense bands observed in PP LYS between 34 and $43 \mathrm{kDa}$ might be ovoglobulins $\left(\mathrm{G}_{2}\right.$ and $\left.\mathrm{G}_{3}\right)$ and flavoprotein that have reported MWs between 30 and 45 $\mathrm{kDa}^{41}$ while the dense band centered at $26 \mathrm{kDa}$ might be ovomucoid and ovoglycoproteins that have reported MWs at 28 and $24 \mathrm{kDa}$, respectively. ${ }^{41}$ Thus, it is possible that the PP LYS might form complexes with the impurities present in egg white, and this affected its release profiles. The interaction of PP LYS with egg white protein impurities might modify its diffusion properties due to changes in its molecular weight and affinity (by hydrophobic or charge-charge interactions) to film matrix. However, the results of this work clearly showed the possibility of controlling release rates of LYS at different purities by using blend film technology in the presence of CAT.

CAT Release Profiles and Antioxidant Potential of Blend Films. The results of release tests conducted to determine release profiles of CAT showed that $72-84 \%$ of CAT existed in soluble form in films (Table 2) while remaining CAT was bound by the film matrix, since this phenolic compound is capable to form $\mathrm{H}$ bonds with zein film matrix. ${ }^{42}$ Thus, the soluble CAT in films formed a significant antioxidant potential that varies between 69 and $81 \mu \mathrm{mol}$ Trolox $/ \mathrm{cm}^{2}$. On the other hand, the release curves clearly showed the effectiveness of the formed blend film structures to reduce release rates of CAT (Figure 3). The zein-fatty acid blend films showed 1.6-2.9-fold lower initial CAT release rates than the control zein film. The highest CAT release rate among blend films was observed for that of zein-LAU films while zein-OLE blend films had the lowest CAT release rates and zein-LIN blend films had intermediate CAT release rates. These results clearly proved that the change of chain length of fatty acids during blend film making could be employed as a highly effective tool to control release rates of both CAT and LYS. Moreover, it is also evident that the $\mathrm{C}_{18}$ fatty acids' number of double bonds and tail conformation (LIN has more bent tail than OLE) that did not affect release rates of LYS is 


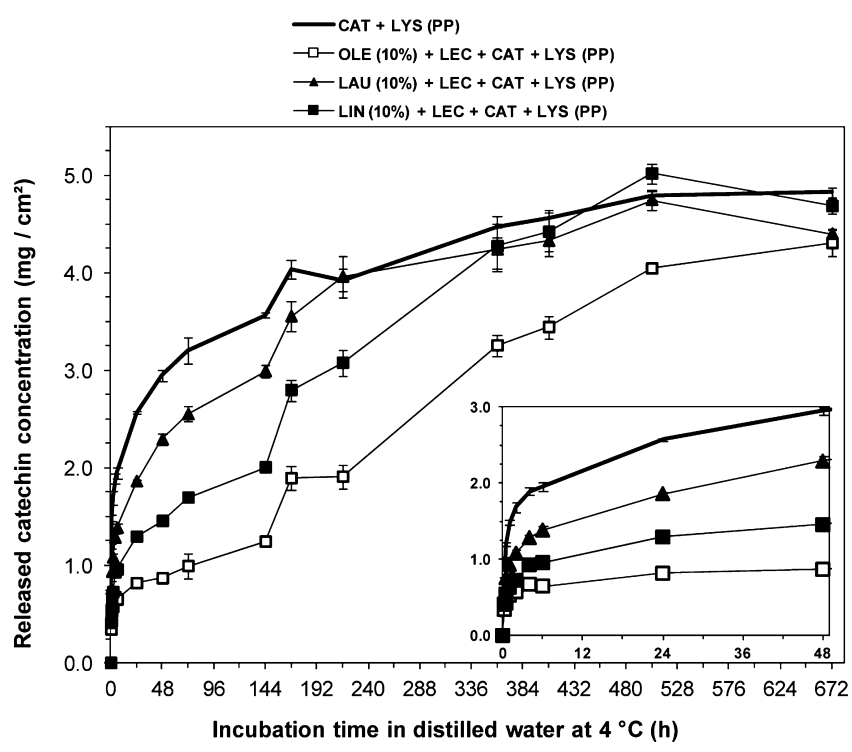

Figure 3. Release profiles of CAT from zein-based films containing PP LYS. CAT: catechin; LYS: lysozyme; OLE: oleic acid; LAU: lauric acid; LIN: linoleic acid; LEC: lecithin.

effective on release rates of CAT. The CAT has a significantly lower molecular weight (MW: $290.3 \mathrm{~g} / \mathrm{mol}$ ) than LYS (MW: $14300 \mathrm{~g} / \mathrm{mol}$ ). However, it is an amphiphilic molecule, and its diffusion properties might change due to its hydrophobic affinity on the aliphatic chains of fatty acids. It appeared that the CAT showed higher hydrophobic affinity to microspheres formed by single double bonded OLE that has a slightly bent tail than those microspheres of double bonded LIN that has an apparently bent tail. In contrast, LYS is a hydrophilic protein, and this might limit its interactions with the hydrophobic tails of fatty acids. These results proved that the developed controlled release mechanism by blend film formation could be employed for delivery of multiple active compounds. Moreover, it is once more proved that the use of fatty acids having different molecular properties could be employed as an effective tool in controlling release profiles of blend films.

Antimicrobial Potential of Films. The results of antimicrobial tests on L. innocua are given in Table 1. The control zein film without LYS and CAT did not form any inhibition zones. In contrast, all other films containing PC or PP LYS showed antimicrobial effect on L. innocua and formed clear zones. Although PC LYS preparation has higher enzyme activity than the PP LYS preparation, there are no significant differences among the clear zone sizes of control zein films containing these enzymes $(P>0.05)$. However, the addition of CAT into films and reduction in their LYS release rate decreased the antimicrobial activity of PC LYS-containing zein control films significantly $(P<0.05)$ while this caused only an insignificant reduction in antimicrobial activity of PP LYScontaining zein control films $(P>0.05)$. Although the CATcontaining blend films with OLE and LIN showed lower LYS release rates than CAT-containing zein control films, there are no significant differences among the antimicrobial activities of these films containing CAT and PC or PP LYS $(P>0.05)$. On the other hand, the CAT-containing zein-OLE and zein-LIN films with sustained LYS release rates had significantly lower antimicrobial activity than PC or PP LYS-containing, but CATlacking zein control films showed the highest LYS release rates. In contrast, blend film making with the potent antimicrobial fatty acid LAU gave films with the highest antimicrobial activity. This result was quite expected, since Hoffman et al. ${ }^{43}$ previously showed the high antimicrobial activity of LAUcontaining zein films against L. monocytogenes. Although the results of this work did not indicate antilisterial activity originated from OLE and LIN in zein films, the OLE and LIN solubilized properly in broth medium were reported to have a limited antimicrobial activity on L. monocytogenes. ${ }^{44}$ However, LAU has reported to have a 6-fold lower minimum inhibitory concentration on L. monocytogenes than OLE and LIN solubilized in broth medium. ${ }^{44}$ The overall results of antimicrobial tests conducted with the classical zone inhibition test could not reflect the effectiveness of developed films in a food system, but they clearly showed the presence of in vitro antimicrobial activity of blend films with sustained LYS release rates and beneficial effects of using antimicrobial fatty acid LAU in blend film making.

Mechanical Properties of Films. In order to analyze their mechanical properties, tensile strength at break, elongation at break, and Young's modulus values of films were determined (Table 3). The control zein films lacking LYS were quite brittle and showed the lowest elongation, but the average tensile strength of these films $(17.67 \mathrm{MPa})$ was significantly higher

Table 3. Mechanical Properties of Zein-Based Blend Films

\begin{tabular}{|c|c|c|c|c|c|c|}
\hline \multicolumn{3}{|c|}{ film composition } & \multirow[b]{2}{*}{ tensile strength at break ( $\mathrm{MPa})$} & \multirow[b]{2}{*}{ elongation at break (\%) } & \multirow[b]{2}{*}{ Young's modulus (MPa) } & \multirow[b]{2}{*}{ film thickness $(\mu \mathrm{m})$} \\
\hline $\mathrm{CAT}\left(\mathrm{mg} / \mathrm{cm}^{2}\right)$ & fatty $\operatorname{acid}^{a}(\%)$ & $\operatorname{LEC}^{a}(\%)$ & & & & \\
\hline- & - & - & $\begin{array}{l}17.67 \pm 0.93 a^{b} \\
\text { PP LYS }(1.4\end{array}$ & $\left./ \mathrm{cm}^{2}\right)$ & $775 \pm 44 a$ & $113 \pm 1$ \\
\hline- & - & - & $10.98 \pm 0.96 b$ & $3 \pm 1 a$ & $530 \pm 32 c$ & $143 \pm 1$ \\
\hline 6.0 & - & - & $0.98 \pm 0.14 c$ & $61 \pm 18 b$ & $55 \pm 12 \mathrm{~d}$ & $167 \pm 1$ \\
\hline 6.0 & 10(OLE) & 10 & $1.17 \pm 0.26 c$ & $53 \pm 9 b$ & $55 \pm 19 d$ & $160 \pm 2$ \\
\hline 6.0 & $10(\mathrm{LAU})$ & 10 & $0.88 \pm 0.10 c$ & $70 \pm 10 b$ & $37 \pm 9 d$ & $159 \pm 2$ \\
\hline 6.0 & $10(\mathrm{LIN})$ & 10 & $\begin{array}{l}1.23 \pm 0.10 \mathrm{c} \\
\text { PC LYS }(0.7\end{array}$ & $\left.\mathrm{g} / \mathrm{cm}^{2}\right)$ & $63 \pm 9 d$ & $192 \pm 5$ \\
\hline- & - & - & $11.02 \pm 0.67 b$ & $3 \pm 1 \mathrm{a}$ & $611 \pm 22 b$ & $119 \pm 3$ \\
\hline 6.0 & - & - & $0.61 \pm 0.06 \mathrm{c}$ & $161 \pm 18 c$ & $28 \pm 5 d$ & $160 \pm 5$ \\
\hline 6.0 & $10(\mathrm{OLE})$ & 10 & $0.52 \pm 0.02 c$ & $164 \pm 17 \mathrm{c}$ & $23 \pm 4 d$ & $162 \pm 8$ \\
\hline 6.0 & $10(\mathrm{LAU})$ & 10 & $0.45 \pm 0.04 c$ & $166 \pm 10 \mathrm{c}$ & $22 \pm 4 d$ & $184 \pm 12$ \\
\hline 6.0 & 10(LIN) & 10 & $0.49 \pm 0.08 c$ & $131 \pm 25 c$ & $22 \pm 6 d$ & $173 \pm 2$ \\
\hline
\end{tabular}

${ }^{a}$ Concentrations of fatty acids and LEC as $\%$ of zein $(w / w) .{ }^{b}$ Different letters in each column show significant difference at $P<0.05$. 
than those of the CAT-containing zein films (0.61-0.98 MPa) and zein-fatty acid blend films $(0.45-1.23 \mathrm{MPa})(P<0.05)$. The addition of LYS reduced the tensile strength and Young's modulus of zein films significantly $(P<0.05)$, but it did not cause any significant change in film elongation $(P>0.05)$. In contrast, the addition of CAT effectively plasticized the zein films and increased their elongation 20-50-fold of that for controls depending on the use of PC or PP LYS. The use of PC or PP LYS did not considerably affect the tensile strength and Young's modulus values of films, but CAT- and PC LYScontaining films showed significantly higher elongation than those containing CAT and PP LYS $(P<0.05)$. The negative effects of PP LYS in flexibility of the plasticized films could be due to its protein impurities that could bind part of the CAT or could cause some local disruptions within the film matrix. However, the CAT-containing films containing PP LYS were not brittle, and they are still much more flexible than the PP LYS-containing but CAT-lacking zein control films. On the other hand, the results of mechanical tests clearly showed that, in the presence of CAT, the blend film making with fatty acids had no considerable additional effect on mechanical properties of films. This result contradicts with those of Santosa and Padua $^{45}$ who reported the plasticizing effects of OLE and LIN on zein. However, these workers produced films from zeinfatty acid resins aggregated in cold water and used OLE and LIN in film composition at $50-100 \%(\mathrm{w} / \mathrm{w})$ of zein.

The factors causing the classical brittleness and flexibility problems of zein films and possibility of using phenolic compounds including CAT in zein film plasticization has been studied recently. Zein films consist of a meshwork that is composed of doughnut structures formed by asymmetric rods joined to each other. ${ }^{46}$ The hydrophobic interactions among asymmetric rods is the primary force that keeps them together and maintains the film integrity, ${ }^{46}$ but these interactions are also responsible for the brittleness and lack of flexibility in zein films. It was recently shown that the phenolic compounds such as CAT and gallic acid could be used effectively for plasticization of zein films and zein-based films such as zeinwax composite and zein-fatty acid blend films. ${ }^{24,38,47}$ It was reported that the zein plasticizing effect of phenolic compounds is due to the formation of $\mathrm{H}$ bonds between the hydroxyl groups of phenolic compounds and the carbonyl group of zein as well as the increased hydrophilicity of films due to increased number of $-\mathrm{OH}$ groups. ${ }^{24,47}$ However, further characterization studies are needed to understand the exact factors effective on mechanical properties and morphologies of zein films.

This work clearly showed the possibility of controlling release rates of both LYS and CAT by using the blend film making technique. The sustained LYS and CAT release mechanisms of developed films were attributed to the encapsulation of a fraction of active compound in microspheres formed within the zein film matrix by blend film making, reduced film porosity caused by CAT and changed affinities of active compounds to modified hydrophilic/hydrophobic balance of film matrix. It was clearly shown that the LYS and CAT release rates of blend films could be changed by changing type and concentration of fatty acid used in blend films. The increase in fatty acid concentration of blend films reduces the LYS release rates. The increased fatty acid chain length is a highly effective factor causing sustained release of both LYS and CAT form the blend films. The formation of blends with $\mathrm{C}_{18: 1}$ more effectively sustained release rates of CAT than blends formed by $\mathrm{C}_{18: 2}$. The release tests also showed the presence of differences in LYS release profiles depending on the purity of the enzyme used in film making. The use of antimicrobial fatty acids like LAU in blend film making served not only to improve the controlled release properties of films but also to support the antimicrobial effect of films. This work showed the possibility of obtaining flexible edible films for controlled release of multiple active compounds. The use of LYS and CAT as active compounds could provide highly functional edible films suitable both for active (antimicrobial and antioxidant) packaging and bioactive packaging. Thus, it is possible to employ such multifunctional films not only to increase safety and quality of food but also to improve the potential health benefits of food.

\section{ASSOCIATED CONTENT}

\section{Supporting Information}

Surface SEM images of developed films (Figure S1); chemical structures of OLE, LIN, and LAU (Figure S2); and SDS-PAGE profiles of increasing concentrations of PC and PP LYS (Figure S3). This material is available free of charge via the Internet at http://pubs.acs.org.

\section{AUTHOR INFORMATION}

\section{Corresponding Author}

*Phone: +90 232 7506292; fax: +90 232 7506196; e-mail: ahmetyemenicioglu@iyte.edu.tr.

\section{Funding}

This work (no. 108M353) was funded by The Scientific and Technical Research Council of Turkey (TÜBİTAK).

Notes

The authors declare no competing financial interest.

\section{ACKNOWLEDGMENTS}

We thank the Materials Research Center and Biotechnology and Bioengineering Research and Applications Center in Izmir Institute of Technology for the generous use of their facilities.

\section{REFERENCES}

(1) Lee, D. S. Antioxidative packaging system. In Innovations in Food Packaging, 2nd ed.; Jung, H. H., Ed.; Academic Press: London, 2013; pp $111-132$.

(2) Lopez-Rubio, A.; Gavara, R.; Lagaron, J. M. Bioactive packaging: Turning foods into healthier foods through biomaterials. Trends Food Sci. Technol. 2006, 17 (10), 567-575.

(3) Appendini, P.; Hotchkiss, J. H. Review of antimicrobial food packaging. Innovative Food Sci. Emerging Technol. 2002, 3 (2), 113126.

(4) Joerger, R. D. Antimicrobial films for food applications: A quantitative analysis of their effectiveness. Packag. Technol. Sci. 2007, 20 (4), 231-273.

(5) Mastromatteo, M.; Mastromatteo, M.; Conte, A.; Del Nobile, M. A. Advances in controlled release devices for food packaging applications. Trends Food Sci. Technol. 2010, 21 (12), 591-598.

(6) Wang, S.; Marcone, M. F.; Barbut, S.; Lim, L.-T. Fortification of dietary biopolymers-based packaging material with bioactive plant extracts. Food Res. Int. 2012, 49 (1), 80-91.

(7) Vuong, Q. V.; Stathopoulos, C. E.; Nguyen, M. H.; Golding, J. B.; Roach, P. D. Isolation of green tea catechins and their utilization in the food industry. Food Rev. Int. 2011, 27 (3), 227-247.

(8) Braicu, C.; Ladomery, M. R.; Chedea, V. S.; Irimie, A.; BerindanNeagoe, I. The relationship between the structure and biological actions of green tea catechins. Food Chem. 2013, 141 (3), 3282-3289.

(9) Mecitoglu, Ç.; Yemenicioglu, A.; Arslanoglu, A.; ElmacI, Z. S.; Korel, F.; Çetin, A. E. Incorporation of partially purified hen egg white lysozyme into zein films for antimicrobial food packaging. Food Res. Int. 2006, 39 (1), 12-21. 
(10) Ünalan, İ. U.; Korel, F.; Yemenicioğlu, A. Active packaging of ground beef patties by edible zein films incorporated with partially purified lysozyme and $\mathrm{Na}_{2}$ EDTA. Int. J. Food Sci. Technol. 2011, 46 (6), 1289-1295.

(11) Duan, J.; Park, S. L.; Daeschel, M. A.; Zhao, Y. Antimicrobial chitosan-lysozyme (CL) films and coatings for enhancing microbial safety of mozzarella cheese. J. Food Sci. 2007, 72 (9), M355-M362.

(12) Min, S.; Harris, L. J.; Han, J. H.; Krochta, J. M. Listeria monocytogenes inhibition by whey protein films and coatings incorporating lysozyme. J. Food Prot. 2005, 68 (11), 2317-2325.

(13) Gemili, S.; Yemenicioglu, A.; Altinkaya, S. A. Development of cellulose acetate based antimicrobial food packaging materials for controlled release of lysozyme. J. Food Eng. 2009, 90 (4), 453-462.

(14) Mendes de Souza, P.; Fernández, A.; López-Carballo, G.; Gavara, R.; Hernández-Muñoz, P. Modified sodium caseinate films as releasing carriers of lysozyme. Food Hydrocolloids 2010, 24 (4), 300306.

(15) Ünalan, İ. U.; Arcan, I.; Korel, F.; Yemenicioğlu, A. Application of active zein based films with controlled release properties to control Listeria monocytogenes growth and lipid oxidation in fresh Kashar cheese. Innovative Food Sci. Emerging Technol. 2013, 20, 208-214.

(16) Han, J. H. Antimicrobial packaging systems. In Innovations in Food Packaging; Jung, H. H., Ed.; Academic Press: London, 2005; pp 80-108.

(17) Buonocore, G. G.; Conte, A.; Corbo, M. R.; Sinigaglia, M.; Del Nobile, M. A. Mono- and multilaver active films containing lysozyme as antimicrobial agent. Innovative Food Sci. Emerging Technol. 2005, 6 (4), 459-464.

(18) Bezemer, J. M.; Radersma, R.; Grijpma, D. W.; Dijkstra, P. J.; Feijen, J.; van Blitterswijk, C. A. Zero-order release of lysozyme from poly(ethylene glycol) poly(butylene terephthalate) matrices. J. Controlled Release 2000, 64 (1-3), 179-192.

(19) de Souza, P. M.; Fernandez, A.; Lopez-Carballo, G.; Gavara, R.; Hernandez-Munoz, P. Modified sodium caseinate films as releasing carriers of lysozyme. Food Hydrocolloids 2010, 24 (4), 300-306.

(20) Park, S. I.; Daeschel, M. A.; Zhao, Y. Functional properties of antimicrobial lysozyme-chitosan composite films. J. Food Sci. 2004, 69 (8), M215-M221.

(21) López de Dicastillo, C.; Castro-López, M. d. M.; López-Vilariño, J. M.; González-Rodríguez, M. V. Immobilization of green tea extract on polypropylene films to control the antioxidant activity in food packaging. Food Res. Int. 2013, 53 (1), 522-528.

(22) López de Dicastillo, C.; Castro-López, M. d. M.; Lasagabaster, A.; López-Vilariño, J. M.; González-Rodríguez, M. V. Interaction and release of catechin from anhydride maleic-grafted polypropylene films. ACS Appl. Mater. Interfaces 2013, 5 (8), 3281-3289.

(23) Gucbilmez, C. M.; Yemenicioglu, A.; Arslanoglu, A. Antimicrobial and antioxidant activity of edible zein films incorporated with lysozyme, albumin proteins and disodium EDTA. Food Res. Int. 2007, 40 (1), 80-91.

(24) Arcan, I.; Yemenicioğlu, A. Development of flexible zein-wax composite and zein-fatty acid blend films for controlled release of lysozyme. Food Res. Int. 2013, 51 (1), 208-216.

(25) Manley, R. H.; Evans, C. D. Binary solvents for zein. Ind. Eng. Chem. 1943, 35 (6), 661-665.

(26) Selling, G. W.; Woods, K. K.; Sessa, D.; Biswas, A. Electrospun zein fibers using glutaraldehyde as the crosslinking reagent: Effect of time and temperature. Macromol. Chem. Phys. 2008, 209 (10), 10031011.

(27) Shukla, R.; Cheryan, M. Zein: The industrial protein from corn. Ind. Crops Prod. 2001, 13 (3), 171-192.

(28) Wang, H.-J.; Gong, S.-J.; Lin, Z.-X.; Fu, J.-X.; Xue, S.-T.; Huang, J.-C.; Wang, J.-Y. In vivo biocompatibility and mechanical properties of porous zein scaffolds. Biomaterials 2007, 28 (27), 3952-3964.

(29) Zhang, B.; Luo, Y.; Wang, Q. Effect of acid and base treatments on structural, rheological, and antioxidant properties of $\alpha$-zein. Food Chem. 2011, 124 (1), 210-220.
(30) Wetter, L. R.; Deutsch, H. F. Immunological studies on egg white proteins: IV. Immunochemical and physical studies of lysozyme. J. Biol. Chem. 1951, 192 (1), 237-242.

(31) Kabara, J. J.; Swieczkowski, D. M.; Conley, A. J.; Truant, J. P. Fatty acids and derivatives as antimicrobial agents. Antimicrob. Agents Chemother. 1972, 2 (1), 23-28.

(32) Laemmli, U. K. Cleavage of structural proteins during the assembly of the head of bacteriophage T4. Nature 1970, 227, 680685 .

(33) Blum, H.; Beier, H.; Gross, H. J. Improved silver staining of plant proteins, RNA and DNA in polyacrylamide gels. Electrophoresis 1987, 8 (2), 93-99.

(34) Padgett, T.; Han, I. Y.; Dawson, P. L. Incorporation of foodgrade antimicrobial compounds into biodegradable packaging films. $J$. Food Prot. 1998, 61, 1330-1335.

(35) Meyers, K. J.; Watkins, C. B.; Pritts, M. P.; Liu, R. H. Antioxidant and antiproliferative activities of strawberries. J. Agric. Food Chem. 2003, 51 (23), 6887-92.

(36) Re, R.; Pellegrini, N.; Proteggente, A.; Pannala, A.; Yang, M.; Rice-Evans, C. Antioxidant activity applying an improved ABTS radical cation decolorization assay. Free Radical Biol. Med. 1999, 26 (9-10), 1231-1237.

(37) ASTM. Standard test method for tensile properties of thin plastic sheeting D882-02. In Annual Book of American Standard Testing Methods; ASTM: Philadelphia, PA, 2002.

(38) Arcan, I.; Yemenicioğlu, A. Incorporating phenolic compounds opens a new perspective to use zein films as flexible bioactive packaging materials. Food Res. Int. 2011, 44, 550-556.

(39) Wang, Q.; Yin, L. L.; Padua, G. W. Effect of hydrophilic and lipophilic compounds on zein microstructures. Food Biophys. 2008, 3 (2), 174-181.

(40) Sugimoto, Y.; Sanuki, S.; Ohsako, S.; Higashimoto, Y.; Kondo, M.; Kurawaki, J.; Ibrahim, H. R.; Aoki, T.; Kusakabe, T.; Koga, K. Ovalbumin in developing chicken eggs migrates from egg white to embryonic organs while changing its conformation and thermal stability. J. Biol. Chem. 1999, 274 (16), 11030-11037.

(41) Belitz, H. D.; Grosch, W.; Schieberle, P. Food Chemistry, 3rd ed.; Springer: Berlin, Germany, 2004; p 553.

(42) Damodaran, S. Amino acids, peptides and proteins. In Food Chemistry, 4th ed.; Fennema, O., Ed.; CRC Press: New York, 1996; pp 217-330.

(43) Hoffman, K. L.; Han, I. Y.; Dawson, P. L. Antimicrobial effects of corn zein films impregnated with nisin, lauric acid, and EDTA. J. Food Prot. 2001, 64 (6), 885-889.

(44) Mbandi, E.; Brywig, M.; Shelef, L. A. Antilisterial effects of free fatty acids and monolaurin in beef emulsions and hot dogs. Food Microbiol. 2004, 21 (6), 815-818.

(45) Santosa, F. X. B.; Padua, G. W. Tensile properties and water absorption of zein sheets plasticized with oleic and linoleic acids. $J$. Agric. Food Chem. 1999, 47 (5), 2070-2074.

(46) Guo, Y. C.; Liu, Z. D.; An, H. J.; Li, M. Q.; Hu, J. Nanostructure and properties of maize zein studied by atomic force microscopy. J. Cereal Sci. 2005, 41 (3), 277-281.

(47) Alkan, D.; Aydemir, L. Y.; Arcan, I.; Yavuzdurmaz, H.; Atabay, H. I.; Ceylan, C.; Yemenicioğlu, A. Development of flexible antimicrobial packaging materials against Campylobacter jejuni by incorporation of gallic acid into zein-based films. J. Agric. Food Chem. 2011, 59 (20), 11003-11010. 